\title{
Impact of Soil Erosion on Production in Cropping Systems. I. Development and Validation of a Simulation Model
}

\author{
M. Littleboy, ${ }^{\mathrm{A}}$ D. M. Silburn, ${ }^{\mathrm{B}}$ D. M. Freebairn, ${ }^{\mathrm{B}}$ D. R. Woodruff, ${ }^{\mathrm{C}}$ \\ G. L. Hammer ${ }^{\mathrm{B}}$ and J. K. Leslie ${ }^{\mathrm{D}}$ \\ A. Land Management Research Branch, Queensland Department of \\ Primary Industries, Meiers Road, Indooroopilly, Qld 4068. \\ B QDPI/CSIRO Agricultural Production Systems Research Unit, \\ P.O. Box 102, Toowoomba, Qld 4350. \\ C Queensland Wheat Research Institute, Queensland Department of \\ Primary Industries, P.O. Box 2282 Toowoomba, Qld 4350. \\ D Queensland Department of Primary Industries, P.O. Box 46, Brisbane, Qld 4001.
}

\begin{abstract}
A computer simulation model to analyse risks of soil erosion to long-term crop production is described. The model, called PERFECT, simulates interactions between soil type, climate, fallow management strategy and crop sequence. It contains six main modules; data input, water balance, crop growth, crop residue, erosion and model output. Modules are arranged in a framework that allows alternative modules to be used as required for the potential range of applications. The model contains dynamic crop growth models for wheat, sorghum and sunflower.

Validation of PERFECT against small catchment and contour bay data collected throughout Queensland showed that PERFECT explained up to $84 \%$ of the variation in total available soil water, $89 \%$ of the variation in daily runoff, and up to $75 \%$ of the variation in grain yield. Average annual soil erosion was accurately predicted but daily erosion totals were less accurate due to the exclusion of rainfall intensity in erosion prediction.

Variability in climate dominates agricultural production in the subtropical region of Australia. The validated model can be coupled with long-term climate and soils databases to simulate probabilities of production and erosion risks due to climatic variability. It provides a method to determine the impact of soil erosion on long-term productivity.
\end{abstract}

Keywords: simulation, water balance, crop growth, erosion, surface management.

\section{Introduction}

The climate of the subtropical region of Queensland and northern New South Wales is one of overlapping influences from the summer rainfall system of the tropics and the winter rainfall system of the temperate zone. These influences produce erratic and highly variable rainfall over the region (Leeper 1970). This variability in rainfall dominates the production system and makes crop production risky (Hammer and Muchow 1990). It also increases risk of soil degradation due to erosion, soil structural decline and loss of fertility (Freebairn et al. 1990).

The unique diversity and flexibility of the cropping systems that have evolved in this region reflect the increased risk to production imposed by this variability in rainfall, with production of winter and summer cereals, coarse grains, oilseeds, grain legumes and fodder crops. The crop sequences and intervening fallow 
strategies are unusually complex. It is an agriculture that can, in different years, display the principles and practices of either temperate or tropical agriculture or of intermediate combinations.

In this environment, evaluating long-term productivity of alternate crop sequences and fallow management strategies is often impractical if relying solely on field experiments. Field trials are expensive and must be run in several environments over a wide range of seasonal conditions to ensure reliable results. However, assessment of new conservation cropping systems can be simplified by using a physically based computer model that simulates interactions between the plant, soil water and management in an agricultural system.

Existing published models are capable of simulating many aspects of a continuous agricultural system. CREAMS (Knisel 1980) was developed to predict non-point source pollution from agricultural areas. Consequently, in CREAMS, major emphasis was placed on surface hydrology, sediment, pesticide movement and nutrient models with no capability of predicting grain yield. EPIC (Williams 1983) was developed to obtain estimates of the long-term effects of erosion on productivity. However, it does not consider cropping systems or fallow management options. EPIC predicts grain yield using simple crop growth models which lack generality for a range of environments. More detailed crop growth models have been developed but these models simulate individual crops and are not included in a cropping systems framework (Jones and Kiniry 1986; Hammer et al. 1987).

Crop models developed for grain growing areas of Queensland and northern New South Wales have been used to predict aspects of agricultural systems. Berndt and White (1976) modified the model of Fitzpatrick and Nix (1969) and used it to evaluate three cropping systems for the Darling Downs region of southern Queensland. Hammer and Goyne (1982) developed a sunflower model and used it to determine phenology, yield and oil quality for a range of planting dates in Queensland. Relationships between time of flowering and wheat yield for a range of crop varieties and planting dates have been described by Woodruff and Tonks (1983). Hammer et al. (1987) described a wheat model and applied the model to examine planting opportunities and simulate wheat yield along an east-west transect of southern Queensland. However, these studies neglected effects of fallow management on the water balance, crop yield and soil erosion, which can be significant for cropping lands in southern Queensland (Freebairn et al. 1990).

A cropping system model that incorporates dynamic crop growth models, a water balance model and an erosion model was required to evaluate production and erosion risks. Such a model must contain dynamic crop growth and grain yield prediction models for a range of crops to evaluate alternate cropping systems. Applications of such a model include:

(i) simulating crop yield, water balance and soil erosion for a cropping system;

(ii) predicting effects of climate, soil type, crop sequence and fallow management on production and erosion;

(iii) examining long-term productivity by simulating effects of erosion on productivity.

The objective of this study was to develop and validate a cropping system model capable of performing these applications for subtropical environments in north-east Australia. 


\section{Model Development}

We developed a cropping systems model called PERFECT (Productivity, Erosion, and Runoff, Functions to Evaluate Conservation Techniques) that integrated dynamics of soil and crop processes. Development of PERFECT has specifically involved:

(i) incorporating a range of dynamic crop growth and grain yield models; initially models for wheat, sunflower and sorghum;

(ii) including a range of simpler crop water use models for applications where dynamic crop models are not available;

(iii) including hydrology and erosion relationships developed using data collected from small agricultural catchments and rainfall simulators;

(iv) using validated components from existing models, particularly CREAMS and EPIC;

(v) including generalized planting and tillage submodels to dynamically determine timing of planting and tillage operations;

(vi) validating model components against experimental data, and validating the entire system model against suitable small catchment data;

(vii) using simple but mechanistic relationships that are biophysically robust.

PERFECT was structured with a modular framework to allow for selection from a range of algorithms and incorporation of new model components. This

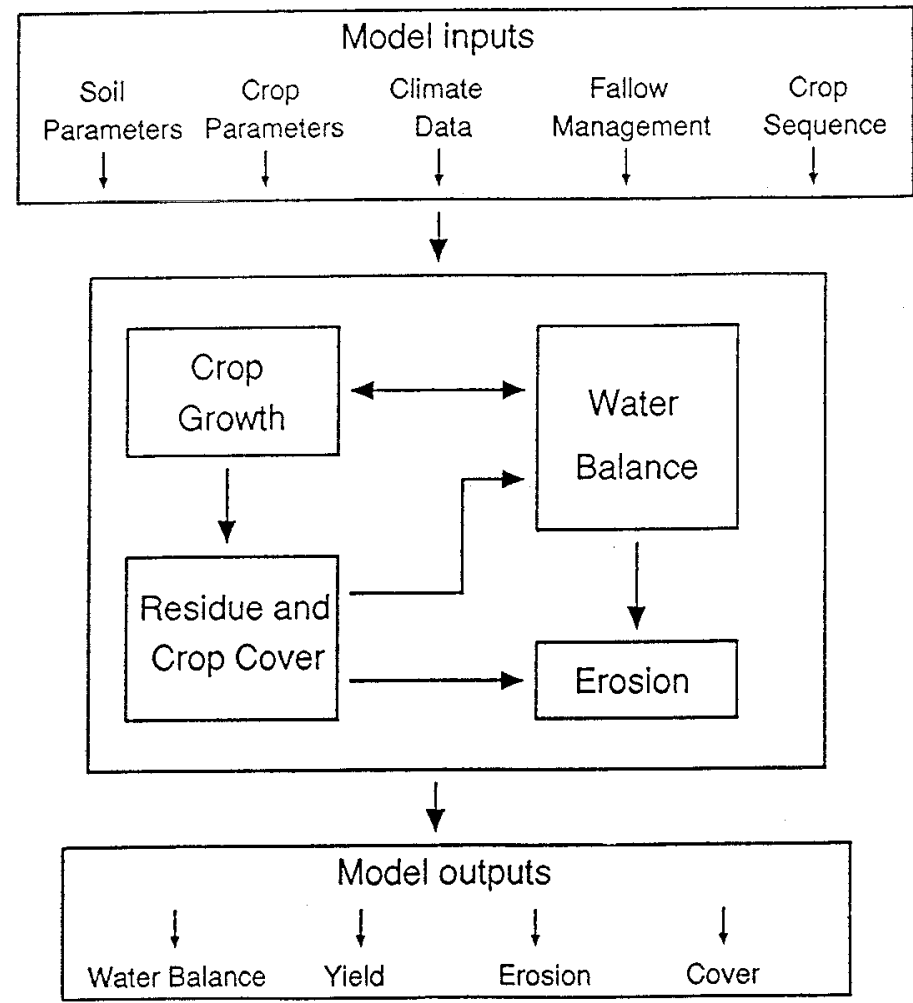

Fig. 1. Internal structure and feedback flows of PERFECT. 
modular framework allows use of alternative water balance, erosion, surface residue, and crop growth components. Overall structure of PERFECT and the internal interaction and feedback flows are shown in Fig. 1. This model contains six major modules that operate on a daily time-step: input data, water balance, crop growth, residue and crop cover, erosion and model output. The following sections give an overview of each module. Further detail of model functions, validation and sensitivity analysis are reported in Littleboy et al. (1989a).

\section{Model Inputs}

PERFECT requires daily climate data, soil parameters, cropping sequence criteria (crop type and length of fallow), crop growth parameters and fallow management (tillage) options. Climate data requirements are daily rainfall, pan evaporation, temperature and solar radiation.

The soil profile is represented by up to 10 layers of variable thickness, with moisture content for each layer at air dry, wilting point, field capacity, and total porosity. Additional parameters describing infiltration and drainage characteristics, evaporation and erosion are required.

Crop sequence parameters are specified by the user and are used to determine the cropping system. PERFECT is capable of evaluating cropping systems that include wheat, sunflower and sorghum either as a continuous monoculture, or rotations including opportunity cropping. Dates of planting can either be specified by the user or generated by the model subject to user-defined planting criteria. Timing of planting is subject to the following criteria: minimum planting rainfall, cumulative dry days from rainfall to planting, plant available water to rooting depth, moisture content in the top profile layer, and the allowable range of planting dates for the crop. Risk of frost or heat stress is not dealt with in the model. Therefore, planting dates need to consider the avoidance of these temperature extremes.

Crop parameters specified by the user allow for selection of different maturity types that determine phenology. Plant density at establishment is also specified by the user.

Fallow management is determined by selection from a range of tillage implements. Tillage operations or herbicide applications can be either specified by the user or generated by the model. The model will generate a tillage operation when conditions are favourable for weed growth. An amount of daily rainfall and soil water content in the top profile layer are used as criteria to determine favourable weed growth conditions.

The model can be run in a 'shell' that provides a user interface to allow easy modification of parameters and viewing of output from multiple simulations.

\section{Water Balance}

The water balance model calculates the volume of water in the soil on a daily time-step and is described by

$$
\mathrm{SW}_{i}=\mathrm{SW}_{i-1}+P-\mathrm{ET}-Q-D,
$$

where $\mathrm{SW}_{i}$ is the soil water content on current day, $i(\mathrm{~mm}) ; \mathrm{SW}_{i-1}$ is the soil water on previous day $(\mathrm{mm}) ; P$ is rainfall $(\mathrm{mm}) ; \mathrm{ET}$ is evapotranspiration $(\mathrm{mm})$; $Q$ is runoff (mm) and $D$ is drainage $(\mathrm{mm})$. 
Fig. 2 shows the structure and interactions of the water balance model within PERFECT. Soil water status is updated daily after accounting for runoff. Infiltration is partitioned to the profile from the surface, filling subsequent layers to total porosity. Soil water redistribution is calculated using either the linear routing and storage algorithm from CREAMS (Knisel 1980), or the linear routing technique of Ritchie (1981). Redistribution from the lowest profile layer is assumed lost to the soil as deep drainage. In dry profiles, infiltration may flow directly into lower profile layers by using an optional soil cracking algorithm. This algorithm assumes that cracks occur when the surface moisture content is less than $30 \%$ of field capacity. Cracks will extend through all profile layers with moisture contents less than $50 \%$ of field capacity.

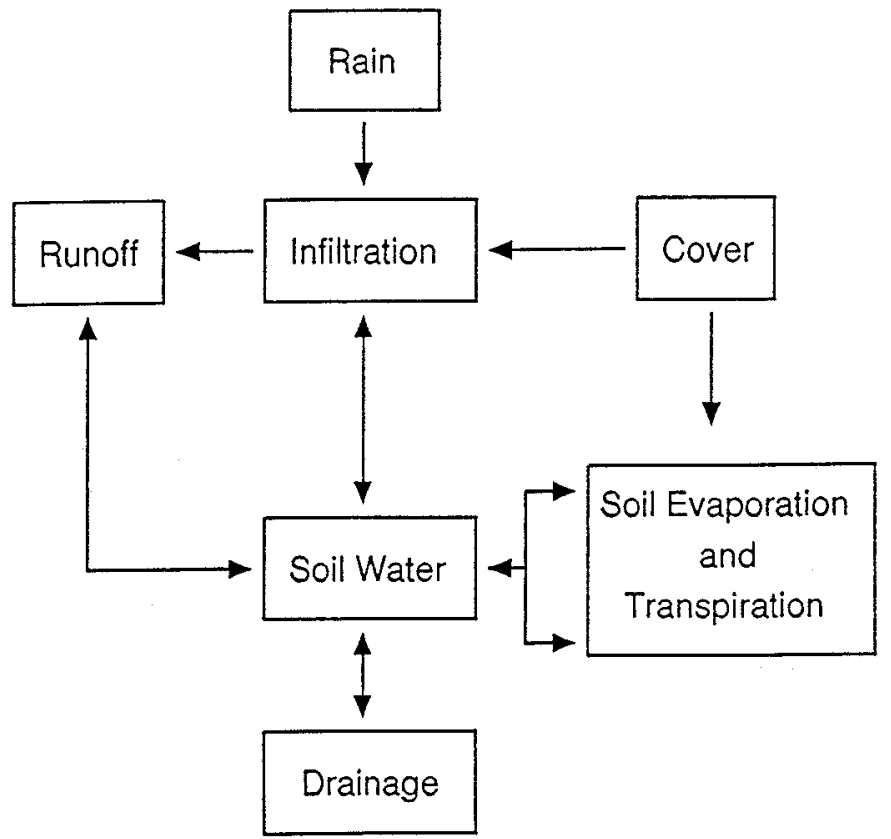

Fig. 2. Internal structure and feedback flows of the water balance component of PERFECT.

The model calculates runoff as a function of daily rainfall, soil water deficit, surface residue cover and crop cover. Three optional techniques included within PERFECT to estimate runoff volume are: the United States Department of Agriculture (USDA) Curve Number technique from Williams and La Seur (1976), the modified Curve Number method from EPIC (Williams 1983) and the Boughton Model (Boughton 1968). The effect of crop residue cover on the USDA Curve Number is estimated using a relationship developed from experiments using a rainfall simulator (Glanville et al. 1984). This relationship assumes that Curve Number decreases by one unit for every $4 \%$ of crop residue cover up to a maximum of $80 \%$ cover.

Soil evaporation is based on Ritchie's two stage evaporation algorithm (Ritchie 1972). Following rainfall, drying occurs at the potential rate to a specified limit (Stage I) then at a rate proportional to the square root of time (Stage II). Evaporation removes soil water from the two upper profile layers and drying 
continues below wilting point to the air-dry limit. We made two modifications to the original Ritchie model. Firstly, stage I drying recommences after any rainfall event but is limited by the amount of infiltration. In the original algorithm (Ritchie 1972), all cumulative Stage II drying had to be replenished by infiltration before Stage I drying could recommence. Secondly, the effect of crop residue on potential Stage I drying rate has been incorporated based on the results of Adams et al. (1976).

Transpiration is calculated as the minimum of potential extraction rate and potential transpiration rate. Potential transpiration is determined from leaf area index and pan evaporation. Potential extraction is calculated from soil water status, root depth, and root density functions. If potential transpiration is less than potential extraction, then water is not limiting. Uptake from each layer is adjusted by the ratio of potential transpiration to potential extraction. If potential transpiration is greater than potential extraction, then water is limiting and an index of water stress on crop growth is calculated as the ratio of potential extraction to potential transpiration (Hammer et al. 1987).

\section{Crop Growth}

PERFECT can simulate crop growth at two levels of complexity:

(i) Static. Ratio of evapotranspiration to pan evaporation, or leaf area index is specified by the user to determine plant water use throughout the year. These types of models are linked with yield prediction equations to give a yield index (Nix and Fitzpatrick 1969).

(ii) Dynamic. For wheat and sunflower, leaf area, crop growth and dry matter are calculated on a daily basis. Crop growth rate is determined from the product of transpiration and transpiration efficiency (Hammer et al. 1987). Leaf area index is calculated from crop growth rate and stage of development and is further modified by a water stress index. Yield is estimated using equations based on dry matter accumulation up to flowering and crop growth rate at flowering (Woodruff and Tonks 1983). Phenology is driven by either cumulative degree days or phenology equations using temperature and photoperiod (Hammer et al. 1982). The structure of the these models is shown in Fig. 3. For sorghum, a dynamic crop model (SORKAM) is used to predict growth and yield of sorghum (Rosenthal et al. 1989). It is similar in structure to the wheat and sunflower models, but crop growth rate is driven by intercepted solar radiation rather than transpiration efficiency.

The wheat component in PERFECT contains the nitrogen model of Woodruff (1984). This can be optionally used to account for nitrogen stress during wheat growth. However, the model does not maintain a continuous long-term nitrogen balance throughout the cropping system.

\section{Soil Erosion}

Erosion is estimated on a daily basis using functions that relate erosion to runoff volume, cover, peak runoff rate, rainfall erosivity, soil erodibility, management practice and topography. Two Modified Universal Soil Loss Equations (MUSLE) (Williams 1975; Onstad and Foster 1975) and two other methods (Rose 1985; 
Freebairn and Wockner 1986) are available. MUSLE functions predict erosion for an event, rather than an average annual basis, and have been evaluated for clay soils in Queensland by Freebairn et al. (1989). The methods of Rose (1985) and Freebairn and Wockner (1986) do not require peak runoff rate or erosivity as inputs. PERFECT is capable of reducing plant available water capacity and mineral nitrogen in the topsoil as erosion occurs, thus allowing it to simulate the effect of erosion on crop production.

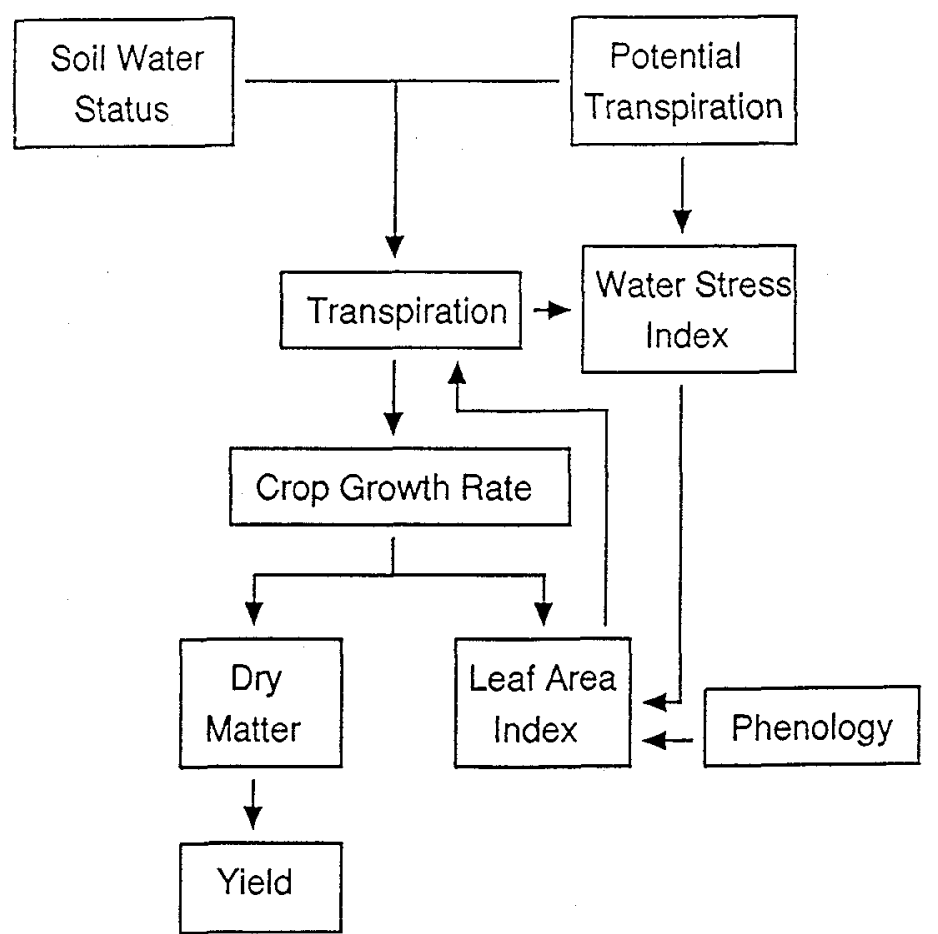

Fig. 3. Internal structure and feedback flows of the crop growth component of PERFECT.

\section{Residue and Crop Cover}

A daily balance of the weight of crop residue on the surface is maintained. At harvest, crop dry matter is added to the residue pool. Residue incorporation during tillage operations and rate of decay of residue are related to previous crop type and tillage implement (Sallaway et al. 1989). The percentage of cover is estimated from residue weight on a daily basis and is used to modify the Curve Number parameter for runoff prediction, the potential evaporation rate in the soil evaporation algorithm, and the amount of soil erosion.

\section{Validation of Model Components}

Validation of PERFECT has occurred at two levels. Firstly, validation of individual model components against detailed field data and secondly, validation of the entire system model against small catchment and contour bay data where soil water, runoff, erosion and yields have been measured for a range of fallow management strategies. 


\section{Water Balance}

The Williams-Ritchie (Williams and La Seur 1976; Ritchie 1972) water balance model used in PERFECT is also used in CREAMS, EPIC and CERES models and has been extensively validated in the United States (see Knisel 1980). Silburn and Freebairn (unpublished data) tested the CREAMS model at two locations in southern Queensland using data from contour bay catchments on a black earth (Greenmount) and a grey clay (Greenwood). Measured wettest and driest soil moisture profiles were used to determine plant available water capacity. Runoff curve numbers were taken from Freebairn and Boughton (1981) with values for some treatments refined by model calibration. Three fallow management practices for annual wheat cropping were simulated at each site; stubble burnt, reduced tillage and zero tillage. Results summarized in Table 1 show that root mean square error (RMSE) ranged from 7 to $9 \mathrm{~mm}$ for runoff and from 26 to $43 \mathrm{~mm}$ for total available soil water in the $0-150 \mathrm{~cm}$ profile. The range of RMSE for available soil water in the profile was similar to that reported by Greacen and Hignett (1984) using a water balance model on similar cracking clay soils.

Table 1. Root mean square error (RMSE) and number of observations $(n)$ for daily runoff and total available soil water in the profile using the CREAMS model at Greenmount and Greenwood (Silburn and Freebairn, unpublished data)

\begin{tabular}{lllcccr}
\hline \multirow{2}{*}{ Location } & \multirow{2}{*}{ Crop } & \multicolumn{1}{c}{ Fallow } & \multicolumn{2}{c}{ Daily runoff } & \multicolumn{2}{c}{ Soil water } \\
& & & $\begin{array}{c}\text { RMSE } \\
(\mathrm{mm})\end{array}$ & $n$ & $\begin{array}{c}\text { RMSE } \\
\text { (mm) }\end{array}$ & $n$ \\
\hline Greenmount & Wheat & Stubble burnt & 8 & 51 & 34 & 31 \\
& & Stubble mulched & 9 & 27 & 35 & 30 \\
& & Zero-tillage & 7 & 37 & 43 & 16 \\
Greenwood & Wheat & Stubble burnt & 8 & 45 & 32 & 17 \\
& & Stubble mulched & 8 & 29 & 28 & 17 \\
& & Zero-tillage & 8 & 29 & 26 & 12 \\
\hline
\end{tabular}

\section{Soil Erosion}

Modified Universal Soil Loss Equation (MUSLE) functions in PERFECT have been validated by Freebairn et al. (1989) for clay soils in Queensland. They found that the MUSLE equations gave reasonable estimates $\left(R^{2}>0.8\right)$ of event erosion using measured hydrologic inputs (runoff depth, peak runoff rate and rainfall erosion index, and $\mathrm{EI}_{30}$ ). Freebairn et al. (1989) concluded that these MUSLE functions are suitable for inclusion in daily models such as PERFECT.

\section{Crop Growth}

The wheat model within PERFECT was originally developed and tested using data from a range of wheat trials across the major wheat growing areas of Queensland (Woodruff and Tonks 1983). The model does not account for yield reductions due to poor crop establishment, frost, insect damage or disease. Therefore, some variation between observed and predicted yield is expected.

Model predictions have been compared with observed wheat yields within Queensland (Hammer et al. 1987). Fig. 4 shows a comparison of calculated 
wheat yields against a 20 year sequence of yield records from a farm near Roma, Queensland. All but one year showed good agreement between predicted and observed wheat yields. The greatly over-predicted yield for the one year was possibly due to frost or disease; factors not accounted for within the model.

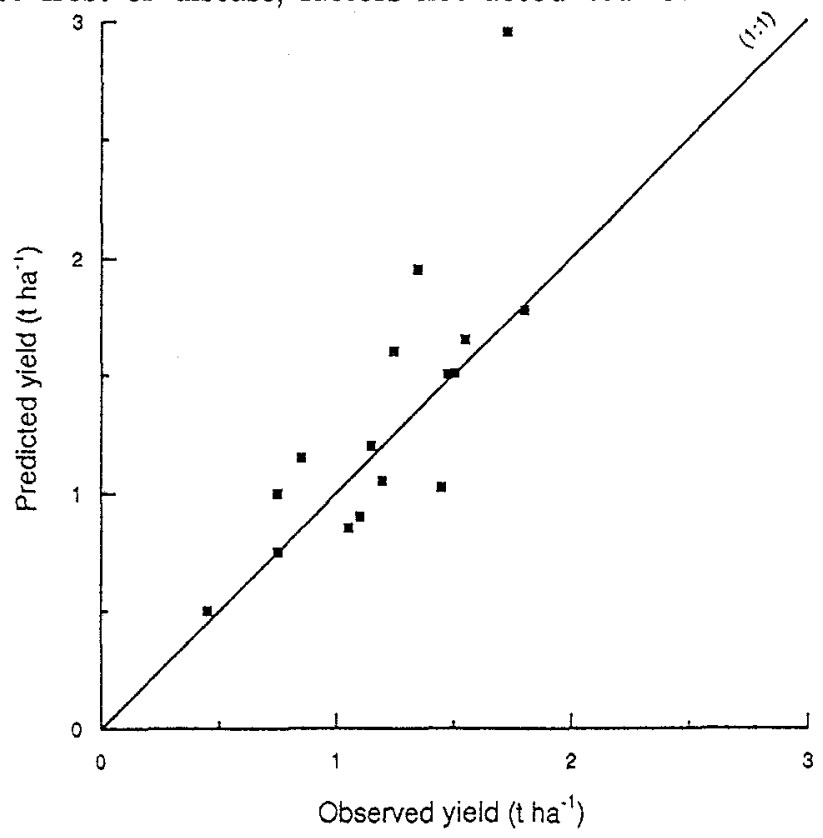

Fig. 4. Comparison of predicted and observed wheat yields at Roma in southern Queensland (Hammer et al. 1987).

The sunflower model was tested on 41 sites in southern and central Queensland (Hammer and Goyne 1982). Yield predictions for 15 sites were unacceptable, with calculated yields under-estimating observed yields. This was attributed to errors in determining plant available water capacity, infiltration rate or rooting depth. Subsequent research has examined the effect of soil type on root depth and a new model (Chapman et al. 1990) incorporating this knowledge is now available.

The sorghum crop model SORKAM was validated on a range of field data from the United States (Rosenthal et al. 1989). Littleboy and Thomas (1990) compared model predictions with experimental data and reported modifications required to adapt SORKAM to Australian subtropical conditions.

\section{Validation of System Model}

Previous sections described the independent validation of model algorithms prior to their incorporation into the cropping systems framework. The following sections describe validation of the entire cropping systems model, PERFECT. This validation is required since it tests both individual model components and internal interactions or feedback.

Results of validation of PERFECT against experimental data collected from small catchments or contour bays at four sites in southern and central Queensland are presented. The experimental sites are near Greenmount (Freebairn and 
Boughton 1981), Capella (Sallaway et al. 1988), Biloela (Thomas et al. 1990) and Theodore (Lawrence 1990). Data collected at these sites encompass the range of crops and fallow managements simulated by PERFECT.

Table 2. Root mean square error (RMSE) and number of observations $(n)$ for daily runoff and total available soil water in the profile using the PERFECT model at Greenmount, Capella, Biloela and Theodore

\begin{tabular}{|c|c|c|c|c|c|c|}
\hline \multirow[b]{2}{*}{ Location } & \multirow[b]{2}{*}{ Crop } & \multirow[b]{2}{*}{ Fallow } & \multicolumn{2}{|c|}{ Daily runoff } & \multicolumn{2}{|c|}{ Soil water } \\
\hline & & & $\begin{array}{l}\text { RMSE } \\
(\mathrm{mm})\end{array}$ & $n$ & $\begin{array}{c}\text { RMSE } \\
(\mathrm{mm})\end{array}$ & $n$ \\
\hline Greenmount & Wheat & $\begin{array}{l}\text { Stubble burnt } \\
\text { Stubble mulched } \\
\text { Zero-tillage } \\
\text { Disc incorporated }\end{array}$ & $\begin{array}{l}6 \\
7 \\
8 \\
4\end{array}$ & $\begin{array}{l}54 \\
42 \\
43 \\
45\end{array}$ & $\begin{array}{l}29 \\
34 \\
43 \\
35\end{array}$ & $\begin{array}{l}31 \\
30 \\
16 \\
30\end{array}$ \\
\hline Capella & Sunflower & $\begin{array}{l}\text { Disc incorporated } \\
\text { Stubble mulched } \\
\text { Zero-tillage } \\
\text { Disc incorporated } \\
\text { Stubble mulched } \\
\text { Zero-tillage }\end{array}$ & $\begin{array}{l}6 \\
8 \\
9 \\
7 \\
7 \\
5\end{array}$ & $\begin{array}{l}24 \\
21 \\
19 \\
31 \\
26 \\
24\end{array}$ & $\begin{array}{l}31 \\
26 \\
38 \\
34 \\
34 \\
25\end{array}$ & $\begin{array}{l}19 \\
19 \\
20 \\
17 \\
15 \\
15\end{array}$ \\
\hline Biloela & Sorghum & $\begin{array}{l}\text { Disc incorporated } \\
\text { Stubble mulched } \\
\text { Zero-tillage }\end{array}$ & $\begin{array}{l}\text { n.a. } \\
\text { n.a. } \\
\text { n.a. }\end{array}$ & $\begin{array}{l}\text { n.a. } \\
\text { n.a. } \\
\text { n.a. }\end{array}$ & $\begin{array}{l}24 \\
24 \\
27\end{array}$ & $\begin{array}{l}53 \\
53 \\
53\end{array}$ \\
\hline Theodore & $\begin{array}{l}\text { Wheat } \\
\text { Pasture }\end{array}$ & Disc incorporated & $\begin{array}{l}3 \\
5\end{array}$ & $\begin{array}{l}14 \\
18\end{array}$ & $\begin{array}{l}25 \\
15\end{array}$ & $\begin{array}{l}28 \\
37\end{array}$ \\
\hline
\end{tabular}

\section{Water Balance}

Comparison of observed and predicted daily runoff and total soil water in the profile for a range of crops and fallow management strategies is given in Table 2 . RMSE ranged from 3 to $9 \mathrm{~mm}$ for runoff and from 15 to $43 \mathrm{~mm}$ for soil water.

At Greenmount, PERFECT was tested using the same period of experimental runoff and soil water data used by Silburn and Freebairn (unpublished data) to test CREAMS. Predictions from PERFECT were noticeably better than from CREAMS for the three fallow managements simulated. For example, for burnt stubble fallow management at Greenmount, CREAMS produced RMSE of $8 \mathrm{~mm}$ for runoff and $34 \mathrm{~mm}$ for soil water (Table 1) compared with RMSE of $6 \mathrm{~mm}$ for runoff and $29 \mathrm{~mm}$ for soil water (Table 2) using PERFECT. The improved predictions are attributed to enhancements in the transpiration and cover algorithms in PERFECT. The crop growth models in PERFECT provide better estimates of transpiration than the leaf area index model contained in CREAMS. PERFECT also predicts effects of surface and crop cover on infiltration and soil evaporation which are ignored in CREAMS.

Observed and predicted daily runoff volume for three experimental sites are shown in Fig. 5. The fourth site, Biloela is omitted because no runoff measurements were made. PERFECT explained $77-89 \%$ of the variation in daily runoff volume. At all sites, there is evidence of estimating small runoff events $(<10 \mathrm{~mm})$ when no runoff occurred, and occasional large errors in estimating a single runoff event. These problems are probably due to the model not incorporating effects of surface roughness and rainfall intensity. 
Observed and predicted total available soil water in the profile for the four experimental sites are shown in Fig. 6. PERFECT explained 75-84\% of the variation in total available soil water. There was no evidence of the model consistently over-estimating or under-estimating soil water, with model predictions scattered uniformly around the 1:1 line. One large error occurred at Theodore where the model overestimated a single soil water measurement by a factor of 2. Further examination of the field data showed that this field measurement occurred during a fallow when tillage was delayed allowing extensive weed growth to occur. It is probable that this large error was due to water use by weeds which was not modelled.

(a) Greenmount

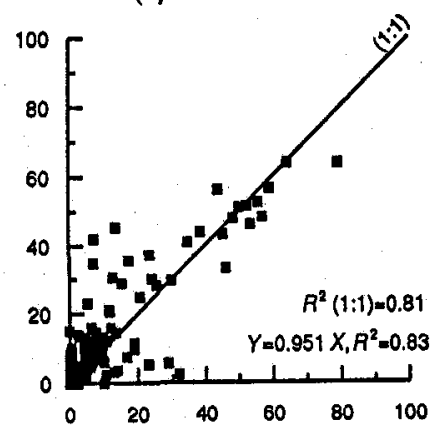

(b) Theodore

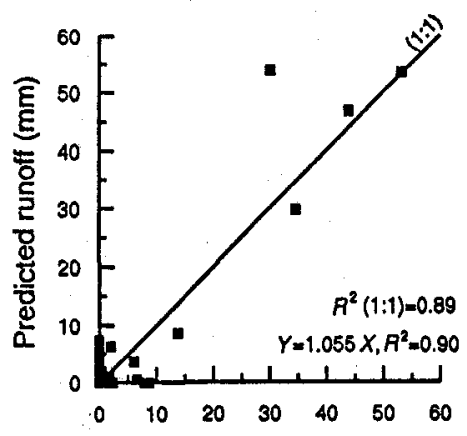

(c) Capella

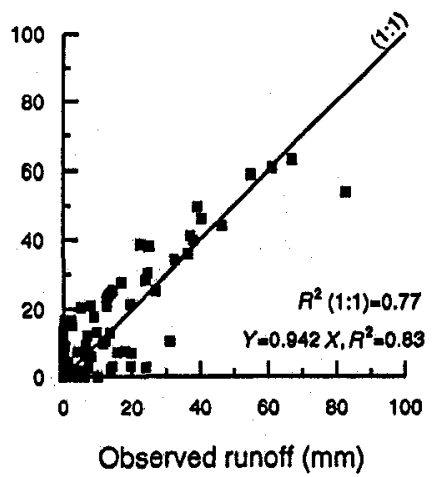

Fig. 5. Predicted and observed daily runoff at (a) Greenmount (1978-1983), (b) Theodore (1985-1987), and (c) Capella (1983-1985). 
a) Greenmount

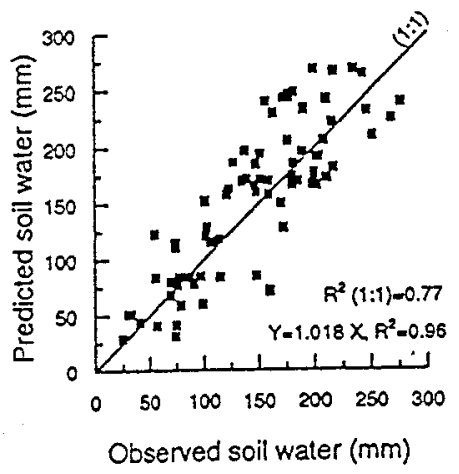

c) Capella

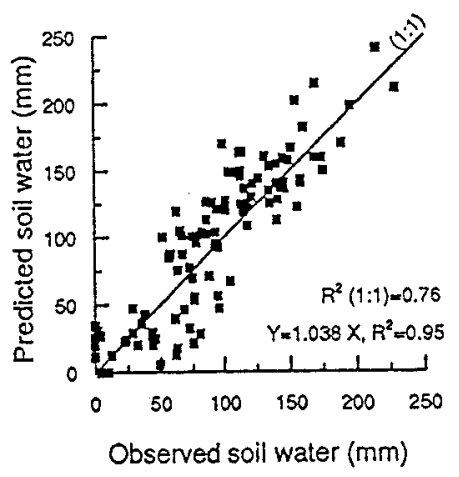

b) Theodore

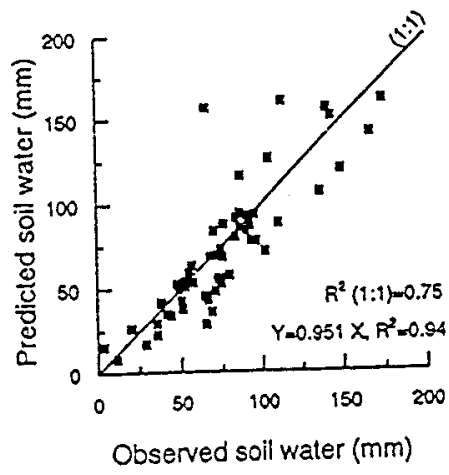

d) Biloela

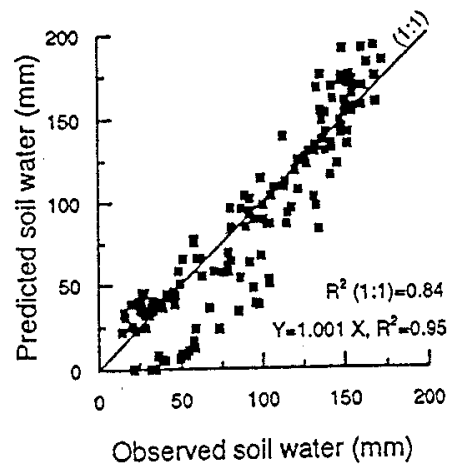

Fig. 6. Predicted and observed total available soil water at (a) Greenmount (1978-1983), (b) Theodore (1985-1987), (c) Capella (1983-1985) and (d) Biloela (1978-1985).

Table 3. Observed and predicted annual erosion $\left(t \mathrm{ha}^{-1}\right)$ for the stubble burnt fallow management at Greenmount for the period 1978-1990

\begin{tabular}{lcccrr}
\hline Year & Observed & Predicted & Year & Observed & Predicted \\
\hline 1978 & $4 \cdot 5$ & $11 \cdot 3$ & 1985 & 0 & 0 \\
1979 & $30 \cdot 6$ & $45 \cdot 2$ & 1986 & $17 \cdot 4$ & $7 \cdot 6$ \\
1980 & $120 \cdot 6$ & $32 \cdot 7$ & 1987 & $14 \cdot 5$ & $3 \cdot 2$ \\
1981 & $99 \cdot 6$ & $91 \cdot 5$ & 1988 & $140 \cdot 0$ & $190 \cdot 0$ \\
1982 & $27 \cdot 6$ & $54 \cdot 8$ & 1989 & $1 \cdot 6$ & $5 \cdot 8$ \\
1983 & $67 \cdot 0$ & $121 \cdot 5$ & 1990 & $8 \cdot 3$ & $19 \cdot 9$ \\
1984 & $24 \cdot 1$ & $14 \cdot 2$ & Mean & $42 \cdot 8$ & $46 \cdot 0$ \\
\hline
\end{tabular}

\section{Soil Erosion}

A comparison of predicted and observed annual erosion for the stubble burnt fallow management treatment at Greenmount is presented in Table 3. Erosion was estimated using the Freebairn cover-concentration function (Freebairn and Wockner 1986). In some years, model predictions are poor but the average 
annual erosion estimated for the 13 years is very similar to the observed value. Variations in the predictions of annual erosion can be explained by examining daily erosion data for the stubble burnt treatment (Fig. 7). The prediction of daily soil erosion was generally poor $\left(R^{2}<0.56, n=77\right)$. However, the poor $R^{2}$ value can be attributed to large prediction errors for some events. Daily erosion is calculated using predicted runoff volume, surface cover and crop cover. Therefore, errors in either runoff or cover prediction will be compounded in erosion predictions. Fig. 5 shows that PERFECT tended to estimate small runoff events on days when no runoff occurred. This trend is also reflected in the estimated erosion. Larger errors in predicted daily erosion can be explained in terms of storm duration and rainfall intensity. For example, Fig. 7 shows that two large errors in predicted erosion at Greenmount are the events dated 5 February 1980 and 21 June 1983. Total rainfall for each event was similar, $91 \mathrm{~mm}$ on 5 February 1980 and $103 \mathrm{~mm}$ for 21 June 1983, but maximum $30 \mathrm{~min}$ rainfall intensity varied by a factor of $10 ; 97.4 \mathrm{~mm} \mathrm{~h}^{-1}$ on 5 February 1980 and $9.6 \mathrm{~mm}^{-1}$ on 21 June 1983. Observed erosion was $100 \mathrm{tha}^{-1}$ on 5 February 1980 and $10.4 \mathrm{t} \mathrm{ha}^{-1}$ on 21 June 1983. This tenfold variation in observed erosion was proportional to the tenfold variation in rainfall intensity. PERFECT does not account for effects of rainfall intensity and consequently predicted similar erosion for the two events; $36 \cdot 1 \mathrm{t} \mathrm{ha}^{-1}$ on 5 February 1980 and $34 \cdot 1 \mathrm{tha}^{-1}$ on 21 June 1983 . Therefore, some events are over-estimated while others, especially large events resulting from high intensity rainfall are under-estimated. However, the predicted average annual erosion for the period 1978-1990 at Greenmount was close to the observed value as shown in Table 3. Since effects of erosion on production are likely to be manifest over years or more probably decades, errors in daily and annual erosion prediction are tolerable and unavoidable when using daily climate inputs.

\section{Stubble burnt}

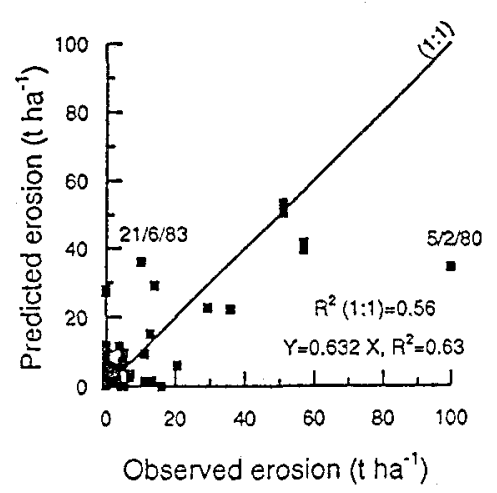

Fig. 7. Predicted and observed daily soil erosion for stubble burnt fallow management at Greenmount for the period 1978 to 1983.

\section{Crop Growth}

Predicted and observed grain yield for the four experimental sites are shown in Fig. 8. PERFECT explained $75 \%$ of the variation in yield at these sites. Observed wheat yield ranged from 1.4 to $3.5 \mathrm{tha}^{-1}$, sorghum yield from 1.8 to $3.8 \mathrm{tha} \mathrm{h}^{-1}$, and sunflower yield from 0.3 to $0.9 \mathrm{tha}-1$. 
Table 4. Observed and predicted average annual wheat yield $\left(\mathrm{t} \mathrm{ha}^{-1}\right)$ at Greenmount (1978-1983) for four fallow management strategies

\begin{tabular}{lcc}
\hline Fallow management & Observed & Predicted \\
\hline Stubble mulched & $2 \cdot 95$ & $2 \cdot 58$ \\
Stubble burnt & $2 \cdot 82$ & $2 \cdot 52$ \\
Stubble incorporated & $2 \cdot 82$ & $2 \cdot 46$ \\
Zero-tillage & $2 \cdot 76$ & $2 \cdot 34$ \\
\hline
\end{tabular}

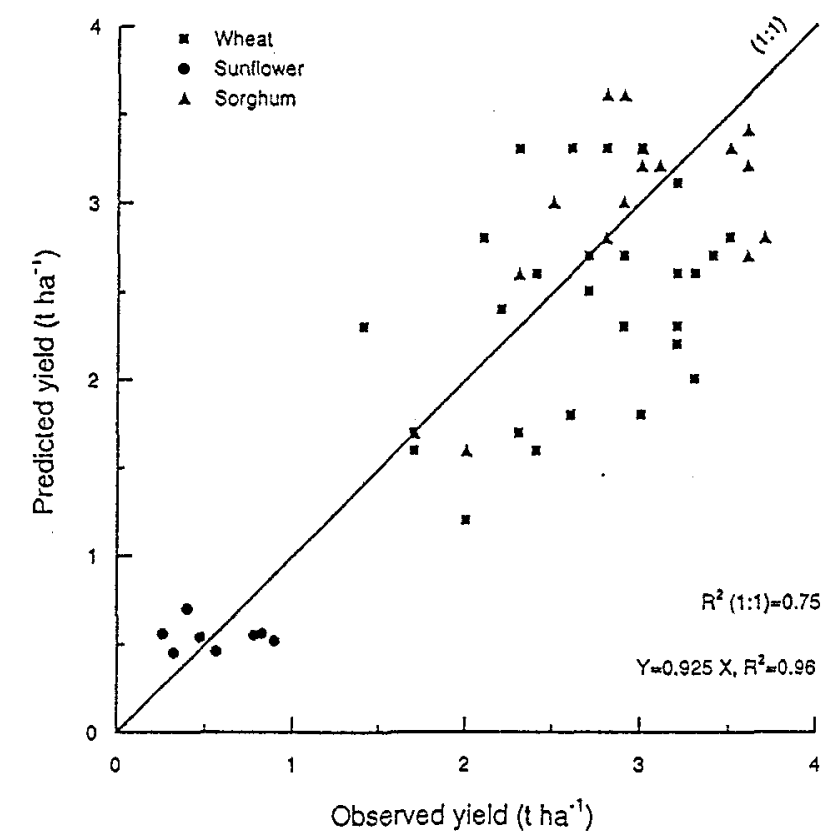

Fig. 8. Predicted and observed grain yield at (a) Greenmount (1978-1983), (b) Theodore (1985-1987), (c) Capella (1983-1985), and (d) Biloela (1978-1985) for wheat, sorghum and sunflower.

Results of simulating effects of fallow management on wheat yield are presented in Table 4. At Greenmount, the model tended to slightly under-estimate average annual wheat yield for all management strategies. However, PERFECT correctly simulated the subtle trends of the effects of management on the average annual yields. The model predicted the following trend in wheat yields: stubble mulch $>$ stubble burnt $>$ stubble incorporated $>$ zero-tillage; this same trend occurred in the observed yields.

Validation of the erosion-productivity component of PERFECT was undertaken by comparing model predictions to field experiments at Inglewood (P. J. White, unpublished data), Miles (P. J. White, unpublished data) and Theodore (L. J. Boaler, unpublished data). At these sites, various depths of topsoil were removed prior to planting to mimic different rates of soil erosion. Differences in crop yields between treatments were attributed to the soil removed. For each experimental site, PERFECT was used to generate the relationship between long-term mean wheat yield and soil removal based on 80 years of historical rainfall data (Littleboy et al. 1989b). Fig. 9 shows the observed and predicted 
(a) Miles

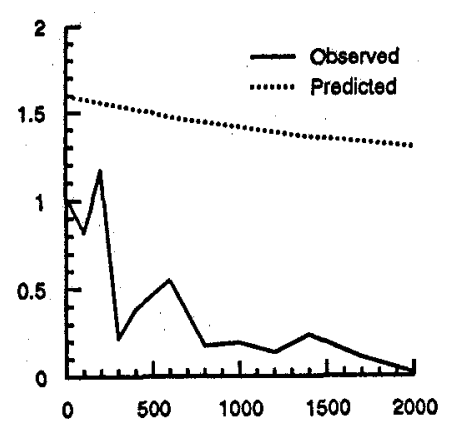

(b) Inglewood

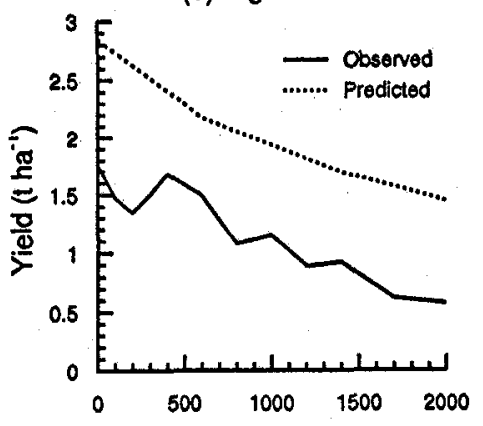

Fig. 9. Relationship between wheat yield and topsoil removal as measured at (a) Miles, (b) Inglewood, and (c) Theodore and compared with mean predicted wheat yields for a series of 80 year simulations.

(c) Theodore

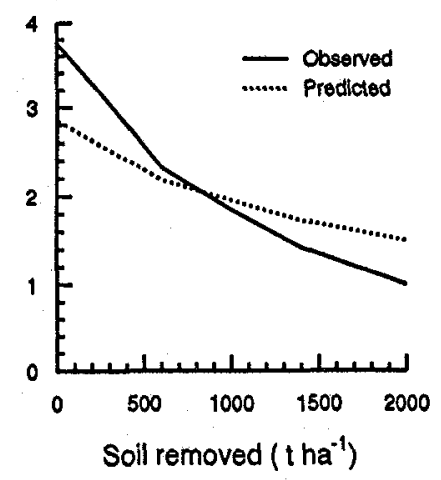

relationships between soil removal and yield decline. At all sites, wheat yield collected from one or two growing seasons is compared with a long-term wheat yield derived from 80 years of rainfall data. Therefore, differences between the observed and predicted yield are expected if the experimental yield is not similar to the long-term mean yield. Measured yield at both Miles and Inglewood were below the long-term average yield reflecting the below average rainfall during the experiment. However, the important feature shown in Fig. 9 is the slope of the relationship between soil removal and yield as this determines the relationship between erosion and productivity. At Inglewood, the observed and predicted lines are roughly parallel, indicating a reasonable simulation of the effect of 
soil removal on yield. At the other two sites, Miles and Theodore, PERFECT under-predicted the rate of yield decline with soil removal, thus providing a conservative estimate of the effect of erosion on productivity.

\section{Discussion}

The cropping system modelling approach presented here integrates research on components of a complex system and enables responses of the entire system to variations in climate, soil and management to be examined. The modular structure of PERFECT allows for upgrading the model as improved submodels are developed.

PERFECT contains algorithms to simulate the water balance, crop growth and yield and erosion for a range of cropping sequences and fallow management strategies. A daily time-step for the model was chosen due to the availability of daily climatic data and because current model algorithms tended to operate on a daily time-step. A shorter time-step water balance model could be incorporated to improve water balance and erosion prediction, but such a model invariably requires a higher level of data than is generally available. However, it is possible that stochastic generation of shorter duration climate data, in particular, rainfall intensity, will lead to improved model predictions of runoff and erosion.

Effects of fallow management on components of the water balance, erosion and yield have been successfully simulated using PERFECT. Model parameters describing the soil, infiltration, evapotranspiration and erosion were not changed to force the model to predict observed data. The effects of fallow management were simulated by inputting the usual tillage operations for each fallow management strategy. The successful prediction of effects of fallow management strategies indicates that interactions between model components are realistic and stable.

PERFECT has been extensively validated against field data collected in north-east Australia. However, although the models are generally physically robust, they were not designed for application beyond the range of environments of north-east Australia. Testing against suitable field data is advisable before using PERFECT in other environments.

Development of PERFECT provides a valuable tool for assessing conservation cropping options by simulating the water balance, crop yield and erosion for combinations of soil type, climate, fallow management strategy and cropping sequence. Long-term predictions can be expressed as probability distributions that reflect risks to production resulting from climatic variability. Inclusion of erosion and soil degradation algorithms allows for analysis of long-term productivity by determining effects of erosion on productivity. Quantification of the relationship between erosion and productivity for three locations in north-east Australia is undertaken in Part II of this series (Littleboy et al. 1992).

\section{Acknowledgments}

We are grateful to Mr L. Boaler, Mr C. Carroll, Mr G. Fossett, Mr P. Lawrence, Mr M. Sallaway, Mr G. Thomas, Dr P. White and Mr G. Wockner for their assistance in providing experimental data used for model validation. Funding was supplied by the Land and Water Resources Research and Development Corporation (formerly National Soil Conservation Program) to finalize model development and the subsequent documentation and validation of PERFECT. 


\section{References}

Adams, J. E., Arkin, G. F., and Ritchie, J. T. (1976). Influence of row spacing and straw mulch on first stage drying. Soil Science Society of America Journal 40, 436-42.

Berndt, R. D., and White, B. J. (1976). A simulation-based evaluation of three cropping systems on cracking-clay soils in a summer-rainfall environment. Agricultural Meteorology 16, 211-29.

Boughton, W. C. (1968). A mathematical catchment model for estimating run-off. Journal of Hydrology (New Zealand) 7, 75-100.

Chapman, S. C., Meinke, H., and Hammer, G. L. (1990). A crop simulation model for a sunflower management decision package. Proceedings of the 8th Australian Sunflower Association Workshop. Kooralbyn, pp. 94-7.

Fitzpatrick, E. A., and Nix, H. A. (1969). A model for simulating soil water regime in alternating fallow-crop systems. Agricultural Meteorology 6, 303-19.

Freebairn, D. M., and Boughton, W. C. (1981). Surface runoff experiments on the eastern Darling Downs. Australian Journal of Soil Research 19, 133-46.

Freebairn, D. M., Littleboy, M., Smith, G. D., and Coughlan, K. J. (1990). Optimising soil surface management in response to climatic risk. In 'Climatic Risk in Crop Production: Models and Management for the Semiarid Tropics and Subtropics'. (Eds R. C. Muchow and J. A. Bellamy.) pp. 283-305. (CAB International: Wallingford.)

Freebairn, D. M., Silburn, D. M., and Loch, R. J. (1989). Evaluation of three soil erosion models for clay soils. Australian Journal of Soil Research 27, 199-211.

Freebairn, D. M., and Wockner, G. H. (1986). A study of soil erosion on Vertisols of the eastern Darling Downs, Queensland. II. The effect of soil, rainfall, and flow conditions on suspended sediment losses. Australian Journal of Soil Research 24, 159-72.

Glanville, S. G., Freebairn, D. M., and Silburn, D. M. (1984). Using curve numbers from simulated rainfall to describe the runoff characteristics of contour bay catchments. Conference on Agricultural Engineering, Bundaberg, Queensland, 27-30 August 1984. Institution of Engineers, Australia.

Greacen, E. L., and Hignett, C. T. (1984). Water balance under wheat modelled with limited soil data. Agricultural Water Management 8, 291-304.

Hammer, G. L., and Goyne, P. J. (1982) Determination of regional strategies for sunflower production. Proceedings 10th International Sunflower Conference, Surfers Paradise, March 14-18, 1982, pp. 48-52.

Hammer, G. L., Goyne, P. J., and Woodruff, D. R. (1982). Phenology of sunflower cultivars. III. Models for prediction in field environments. Australian Journal of Agricultural Research 33, $263-74$.

Hammer, G. L., and Muchow, R. C. (1990). Quantifying climatic risk to sorghum production in Australia's semiarid tropics and subtropics: Model development and simulation. In 'Climatic Risk in Crop Production: Models and Management for the Semiarid Tropics and Subtropics'. (Eds R. C. Muchow and J. A. Bellamy.) pp. 204-32. (CAB International: Wallingford.)

Hammer, G. L., Woodruff, D. R., and Robinson, J. B. (1987). Effects of climatic variability and possible climatic change on reliability of wheat cropping-A modelling approach. Agricultural and Forest Meteorology 41, 123-42.

Jones, C. A., and Kiniry, J. R. (1986). 'CERES-MAIZE: A Simulation Model of Maize Growth and Development.' (A\&M University Press: Texas.)

Knisel, W. G. (1980). 'CREAMS: A Field-Scale Model for Chemicals, Runoff, and Erosion from Agricultural Management Systems.' United States Department of Agriculture, Conservation Research Report 26.

Lawrence, P. A. (1990). M.Sc. Thesis, School of Australian Environmental Studies, Griffith University, Nathan, Queensland.

Leeper, G. W. (1970). Climates. In 'The Australian Environment'. (Ed. G. W. Leeper.) pp. 12-20. (CSIRO Aust.: Melbourne.)

Littleboy, M., Silburn, D. M., Freebairn, D. M., Woodruff, D. R., and Hammer, G. L. (1989a). PERFECT, A computer simulation model of Productivity, Erosion, Runoff Functions to Evaluate Conservation Techniques. Queensland Department of Primary Industries, Bulletin QB89005. 
Littleboy, M., Coughlan, K. J., Silburn, D. M., and Boaler, L. J. (1989b). Modelling erosion productivity relationships. 5th Australian Soil Conservation Conference, 11-13 September 1989, Perth, Western Australia.

Littleboy, M., Silburn, D. M., Freebairn, D. M., Woodruff, D. R., and Hammer, G. L. (1992). Impact of soil erosion on production in cropping systems. II. Simulation of production and erosion risks for a wheat cropping system. Australian Journal of Soil Research 30, 775-88.

Littleboy, M., and Thomas, G. A. (1990). Application of SORKAM model in Central Queensland. International Symposium on Climatic Risk in Crop Production: Models and Management for the Semiarid Tropics and Subtropics, Brisbane, Australia, 2-6 July 1990. Contributed Papers Volume, pp 20-1.

Nix, H. A., and Fitzpatrick, E. A. (1969). An index of crop water stress related to wheat and grain sorghum yields. Agricultural Meteorology 6, 321-37.

Onstad, C. A., and Foster, G. R. (1975). Erosion modelling on a watershed. Transactions, American Society of Agricultural Engineers 18, 288-92.

Ritchie, J. T. (1972). A model for predicting evaporation from a row crop with incomplete cover. Water Resources Research 8, 1204-13.

Ritchie, J. T. (1981). Soil water availability. Plant and Soil 58, 327-38.

Rose, C. W. (1985). Developments in soil erosion and deposition models. Advances in Soil Science 2, 1-63.

Rosenthal, W. D., Vanderlip, R. L., Jackson, B. S., and Arkin, G. F. (1989). SORKAM: A Grain Sorghum Crop Growth Model. Texas Agricultural Experimental Station Computer Software Documentation Series, MP1669. (Texas A \& M University: Texas.)

Sallaway, M. M., Lawson, D., and Yule, D. F. (1989). Ground cover during fallow from wheat, sorghum and sunflower stubble under three tillage practices in Central Queensland. Soil and Tillage Research 12, 347-64.

Sallaway, M. M., Yule, D. F., Lawson, D., Carroll, C., Fossett, G., Burger, P., and Nickson, D. (1988). Runoff and soil loss study, Capella, Central Queensland. Queensland Department of Primary Industries, Project Report Q088012.

Thomas, G. A., Standley, J., Webb, A. A., Blight, G. W., and Hunter, H. M. (1990). Tillage and crop residue management affect Vertisol properties and grain sorghum growth over seven years in the semi-arid tropics. 1. Crop residue and soil water during fallow periods. Soil and Tillage Research 17, 181-97.

Williams, J. R. (1975). Sediment-yield prediction with universal equation using runoff energy factor. In 'Present and Prospective Technology for Predicting Sediment Yields and Sources'. pp. 244-52. United States Department of Agriculture, ARS-S-40.

Williams, J. R. (1983). 'EPIC, The Erosion-Productivity Impact Calculator, Volume 1. Model Documentation.' Agricultural Research Service, United States Department of Agriculture.

Williams, J. R., and La Seur, W. V. (1976). Water yield model using SCS curve numbers. Journal of Hydraulics Division, American Society of Civil Engineers 102, 1241-53.

Woodruff, D. R. (1984). Crop modelling in DPI - nutrients. In 'Crop Nutrition and Related Topics Relevant to Queensland'. (Ed. W. M. Strong.), Queensland Department of Primary Industries, Conference and Workshop Series QC84013.

Woodruff, D. R., and Tonks, J. (1983). Relationship between time of anthesis and grain yield of wheat genotypes with differing developmental patterns. Australian Journal of Agricultural Research 34, 1-11. 